\title{
Destructive Impacts of Social Media and Mass Media on Psychological Attitudes and Behaviors towards COVID-19
}

\author{
Qudsia Umaira Khan* \\ CMH Lahore Medical College and Institute of Dentistry (NUMS), Pakistan
}

*Corresponding author: Qudsia Umaira Khan, CMH Lahore Medical College and Institute of Dentistry (NUMS), Lahore, Pakistan

\section{ARTICLE INFO}

Received: 蔧April 15, 2021

Published: 慧 April 26, 2021

Citation: Qudsia Umaira Khan. Destructive Impacts of Social Media and Mass Media on Psychological Attitudes and Behaviors towards COVID-19. Biomed J Sci \& Tech Res 35(2)-2021. BJSTR. MS.ID.005686.

Keywords: COVID-19 Pandemic; Social Media Impacts; Coronavirus Infodemic; Psychological COVID-19 Disturbances

\section{ABSTRACT}

In the little time after the emergence of the novel coronavirus disease (COVID-19) in China, the deceptive gossips and conspiracy concepts about the pandemic, surveillance, death rates, and (removed word-regarding) threats are closely associated with social media and mass media. Since the outbreak started in fall 2019, till now approximately $114291,102,041,000$ (people have died across the globe. The choices on quarantine applying must be based on the authentic accessible resources. Most of the studies reported adverse psychological impacts such as post-traumatic stress, confusions, anger, fear of infections, and frustrations as long-lasting paraphernalia during the largest quarantine period. The striking fastidiousness of such catastrophe is the fluke of virality and virology which are spreading very rapidly than that of the virus itself is the misinformation about the outbreak. Thus, obstructing such fabrication about the outbreak is necessary as it might become the most contagious in the coming times. Multiple social media scrutinizes and discussions regarding the geographically pandemic situation including tweets, messages, posts in the form of real-time maps have been used as an information source in the major communication campaigns. To minimalize such psychological fallouts, it is recommended that administrators must take steps to make quarantines as little as possible by providing clear information and rationale about quarantine etiquettes and ensure people in isolation have access to adequate goods. The majority of the people only experience COVID-19 through social and mass media ever. 24/7 coverage of multiple media resources makes it looks like the pandemic is ubiquitous for the lives. World Health Organization (WHO) coined a term by "Infodemic" that refers to spreading the disinformation on the COVID-19. The disassortative scenarios created by illiteracy and snowballing uncertainty raised the volume of fear in the minds of people. Giving guidance on actual social media usage to find definitive information should provide an update through confident resources particularly from the official institutes and organizations of governments. The suggestions including following WHO and CDC statistics have been recommended to accomplish news authenticity must be brought to control the stress of COVID-19.

\section{Introduction}

COVID-19 is an infectious disease that is caused by coronaviruses that belong to the family of viruses that cause diseases in animals as well as humans (Anderson et al., 2020). This disease emerged in China in 2019, and it was unknown before the outbreak in China. COVID-19 has spread globally, and yet multiple specifications need optimization and boosting in clinical course and management during COVID-19 [1]. The symptoms of COVID-19 include shortness of breath, fever, cough, sore throat, loss of taste, muscle aches, as well as loss of smell. Using an alcohol-based sanitizer or washing hands frequently for 20 seconds can protect you from this pandemic disease [2]. Coronavirus is a respiratory virus that typically outspreads through droplets of saliva or nasal discharge of an infected person while coughing and sneezing [3]. 
Coronavirus disease or COVID-19 has become a potentially fatal disease and great health concern globally as it is considered to be a zoonotic origin and many people that are infected by this disease had exposure to the wet animal market of Wuhan, a city of China. The disease has proven to be a person-to-person transmitting disease [4]. Therefore, steps have been taken for the isolation of victims of these diseases and are subjected to relevant treatment methodologies. Certain measures are being taken to reduce its transmission to control the outbreak of this disease. A group of people that are likely to be more susceptible to diseases needs more protection [5]. A huge drawback caused due to the outspread amount of misinformation has immensely and eventually devastated the developmental optimization of the system. The aim of representing this is to involve the basic scientific facts of SARSCoV-2 and the inclusion of its clinically reported presentation. It sticks to the objective of representing the interventions and developments at public health and epidemiological levels [1].

Mass media is one of the most strategic tools in the management of disasters. It can solve things as well as it can make the situation worse. So, calculated planning is required to turn the mass media into an effective tool to solve problems. Disaster creates an imbalance in natural life and media is an important tool to improve the involvement of society by creating new sights during a disaster [6]. The current study focuses on the role of mass media in the COVID-19 situation. The COVID-19 has become terrifying and spreading in swift ways. At present, no vaccines are developed, and the mysterious fact is that how much deadly it stands actually. Under such situations, it's comprehensible that people must understand the obvious impacts of social and mass media on Covid-19 [7]. In terms of entire coverages of higher-ranked diplomats and leaders of states, the perceptions engendered by the media have the higher impacts on the progression of international relations. The panic due to coronavirus and the intensely inconsistent publicly issued media reports without any mentioning lot of the struggles of scientific communities have created challenges for the global public by disrupting their feelings [8]. Since the outbreak started in fall 2019, till now approximately 114,291(102,041,000) people have died across the globe (Figure 1). Meanwhile, the journalism catastrophe has not stopped yet as the persistent reporting of every individual of dying with COVID-19 and leaving out the deaths from several other sicknesses, social violence, and suicides are intended for exciting the terror more than to inspire a rational public deliberation [9]. Moreover, the media has also bowed a blind eye on the enduring destructions of public health services, general insurances, and medicinal privatization which have been compromised the global responses to all types of diseases. Likewise, the serious challenge of providing healthcare and nutrition for the poor workers and the homeless people is also agreed by media over in silences [10].

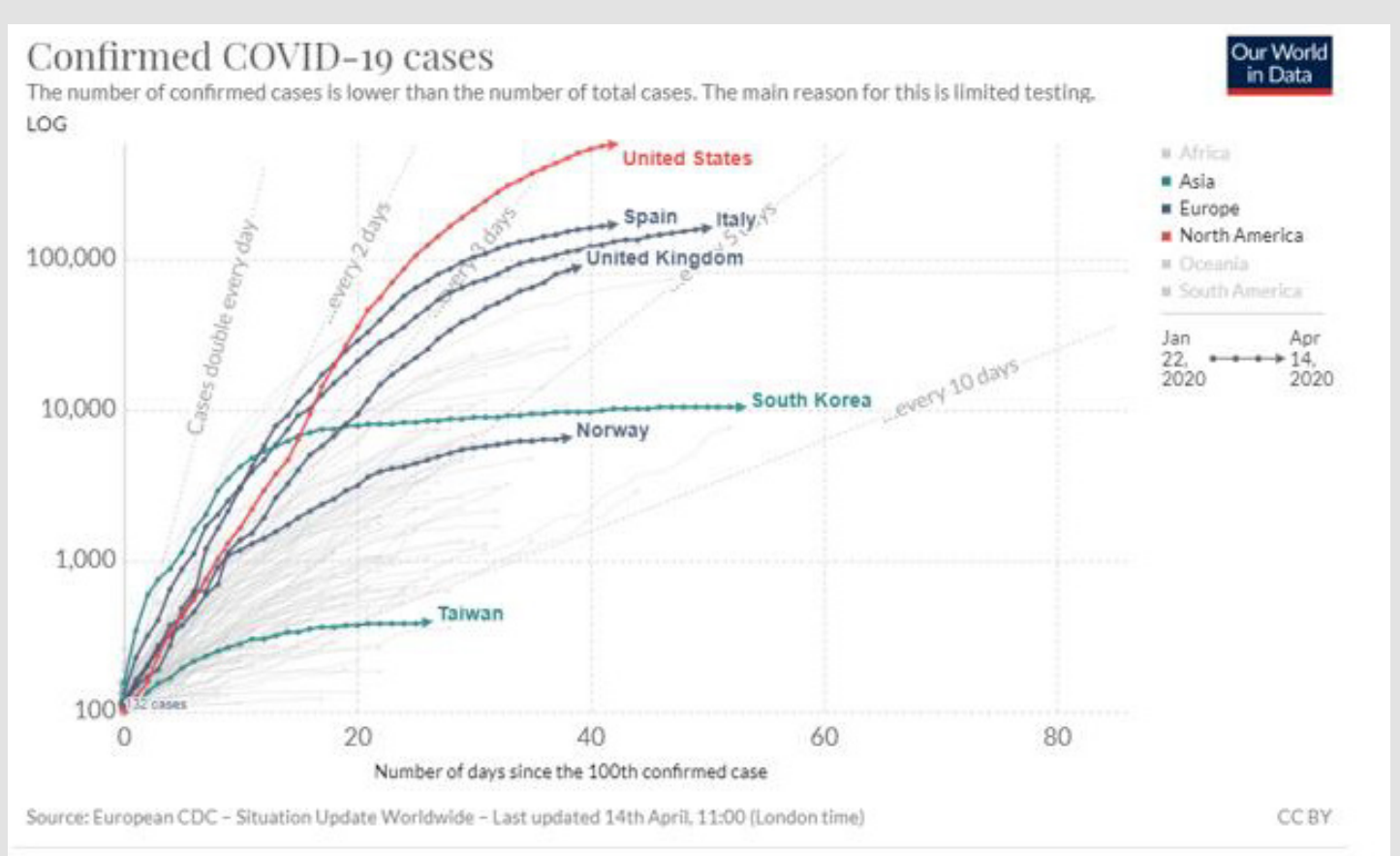

Figure 1: Imports from China [24].

Since the National Health Commission officially recognized COVID-19 as a Class-B infectious illness, it has impacted the psychological conditions of people across the globe. During the COVID-19 outbreak in China, a study conducted during January 2020 on sentiment analysis has acquired the psychological data and found significant variations. The findings exposed that the apprehensions of people in terms of linguistic expressions have been rapidly increased and an upsurge in family and health reservations [11]. The vagueness of the imminent situation causes cognitive insecurity and dissonance which produces a sensation 
of mental distress that leads towards the reduction in oriented activities and dissension and security trusts in family and health relationships [12]. Moreover, people behave in a more conservative and reticent way on feeling COVID-19 threats. The Director-General of WHO Dr. Tedros referred to it as a war against "conspiracy and trolling theories" [13]. The American Psychological Association reported vigorous evidence that social isolation and solitude during COVID-19 significantly increased the magnitudes of premature mortality risks and confirmed through various leading health indicators. Since the advent of the Zika virus in 2016, the risk perception was studied which showed that as the public read more regarding the viral pandemic on social media, their risk perceptions rapidly intensified [14].

As on increasing the bulk of data about Zika on conventional media, the people were more prospective to engross in protecting manners. It was suggested that public health interventions can trust on social media for quick awareness-raising about such threats by avoiding the sharing confusions about updates and developments [15]. In the current COVID-19 pandemic, still, the constant flood of information on mass and social media is characteristically diverse from the real circumstances. In 2013, after the Boston Marathon bombings, it was found that the people with robust media exposure on attack coverage had more acute stresses as compared to those who were exposed directly to the bombings [16]. Likewise, the people found negative psychological impacts like post-traumatic stress, anger, and confusion during COVID-19 media reporting. To minimalize such psychological fallouts, it is recommended that administrators must take steps to make quarantines as little as possible by providing clear information and rationale about quarantine etiquettes and ensure people in isolation have access to adequate goods [17]. Another adversative impact of sensationalized or excessive exposure to media is that it leads the public to involve in misguided tries for health protection which affect badly the happiness and healthiness. In the past epidemics, the emergency hospital systems development was one of the most effective crisis measurements to control epidemic overload while during COVID-19, people rush towards getting different treatments and feeling fears even in the lack of critical symptoms. It led to shortages of drugs for the patients who depend upon the daily dosages. Too much media exposure drives the panic towards hoarding and buying behaviors which can aggravate the sagacity of threat or scarcity [18].

COVID-19 has become the definitive disruptor due to the characteristic property of reforming the work lives, family dynamics, and finances of people. Confronting the media exposure problems which can cause psychological and emotional stress to an individual's relationships [10]. It is important to ensure the true prevalence of COVID-19. The majority of the people only experience COVID-19 through social and mass media ever. As 24/7 coverage of multiple media resources makes it looks like the pandemic is ubiquitous for the lives [17]. The research also demonstrates that the perceptions of the proportion of negative thoughts of viral infection are influencing heavily by due to reading and watching social media news. World Health Organization (WHO) coined a term by "Infodemic" that refers to spreading the disinformation on the COVID-19. It makes it hard for people to find a resolute resource for obtaining exact information as people are encountering a mess of coronavirus reading data on social media [19] (Figure 2).

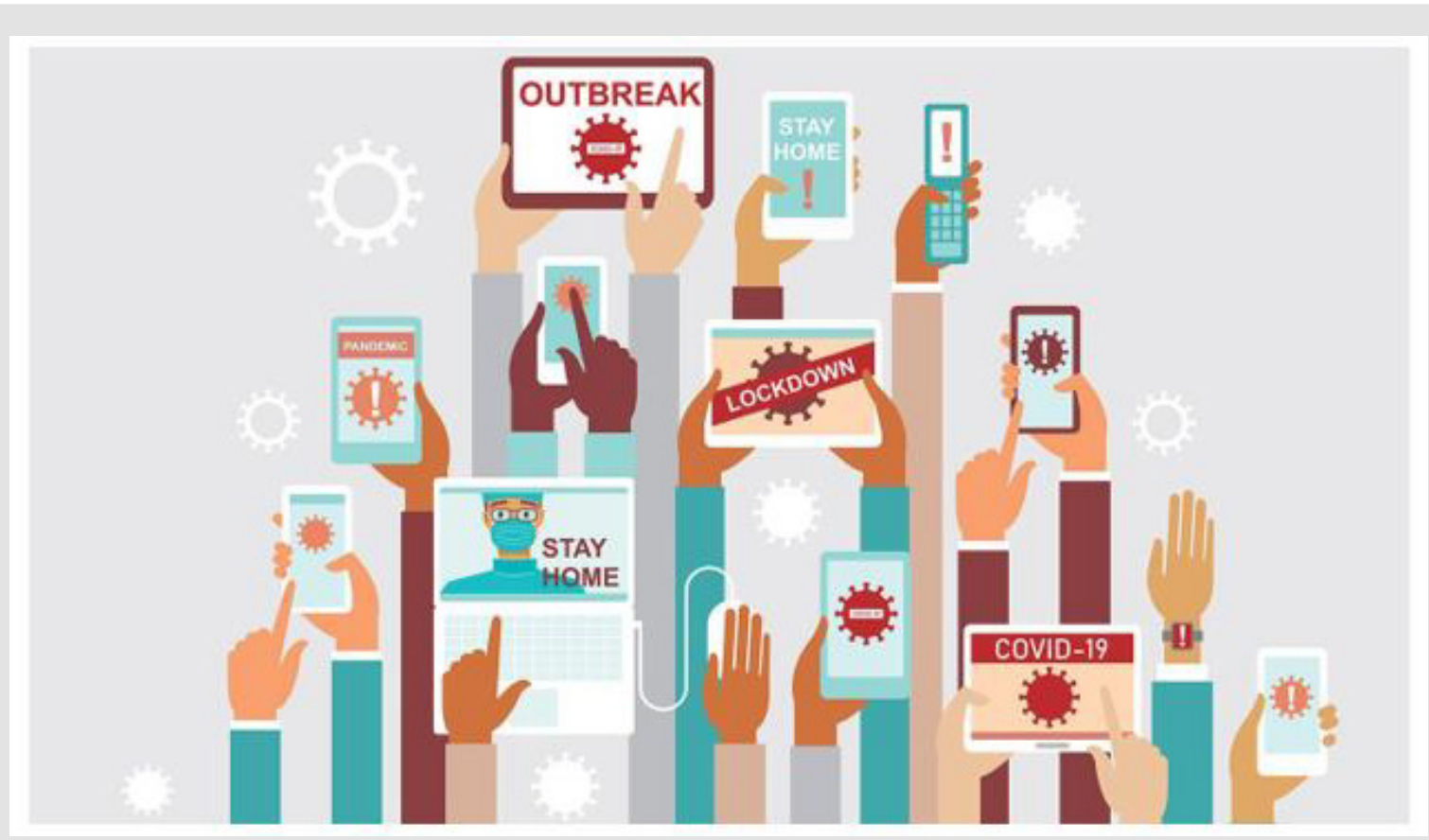

Figure 2: Infodemic of COVID-19 (resourced from Hub - Johns Hopkins University). 
Misleading posts regarding hygiene, cleanings, disinfections, and food are simply shared on social media. So, people must only give attention to their fundamental needs within their stay at home. The disassortative scenarios created by illiteracy and snowballing uncertainty raised the volume of fear in the minds of people. Giving guidance on actual social media usage to find definitive information should provide an updated through confident resources particularly from the official institutes and organizations of governments. The WHO and CDC have developed webpages for myth busters to discourse and correct the distortion about the COVID-19 outbreak. The mass panic can only be tackled with the help of such data records $[20,21]$. The suggestions to accomplish news consumption as a mode to brought stemming the stress of COVID-19 included:

a) Don't watch TV news for every update regarding COVID-19 in self-isolation or quarantine.

b) Confirm the news sensibly from trustworthy journalism administrations and the Center for Disease Control and Preventions.

c) Keep in mind that the content of social media COVID-19 accounts sources of spreading news is not regulated and can comprise conjecture and conspiracies.

\section{Contributions}

Both authors in the parts of COVID-19 media impacts are consortium and equally contributed to this review paper.

\section{Conflict of Interest}

None.

\section{References}

1. Liu Y, Gayle AA, Wilder-Smith A, Rocklöv J (2020) The reproductive number of COVID-19 is higher compared to SARS coronavirus. J Travel Med 27(2): taaa021.

2. Novel CPERE (2020) The epidemiological characteristics of an outbreak of 2019 novel coronavirus diseases (COVID-19) in China. Zhonghua liu xing bing xue za zhi= Zhonghua liuxingbingxue zazhi 41(2):145-151.

3. Heymann DL, and Shindo N (2020) COVID-19: what is next for public health? Lancet 395 (10224): 542-545.

4. Bedford J, Enria D, Giesecke J, Heymann DL, Ihekweazu C, et al. (2020) COVID-19: towards controlling a pandemic. Lancet 395(10229): 10151018.

\section{ISSN: 2574-1241}

DOI: $10.26717 /$ BJSTR.2021.35.005686

Qudsia Umaira Khan. Biomed J Sci \& Tech Res

This work is licensed under Creative

Commons Attribution 4.0 License

Submission Link: https://biomedres.us/submit-manuscript.php
5. Wu J, Liu J, Zhao X, Liu C, Wang W, et al. (2020) Clinical Characteristics of Imported Cases of COVID-19 in Jiangsu Province: A Multicenter Descriptive Study. Clin Infect Dis an Off Publ Infect Dis Soc Am.

6. Cinelli M, Quattrociocchi W, Galeazzi A, Valensise CM, Brugnoli E, et al. (2020) The covid-19 social media infodemic. arXiv Prepr arXiv2003.05004.

7. (2013) Media C on C. Children, adolescents, and the media. Pediatrics 132(5): 958-961.

8. Sun K, Chen J, Viboud C (2020) Early epidemiological analysis of the coronavirus disease 2019 outbreak based on crowdsourced data: a population-level observational study. Lancet Digit. Heal 2(4): 201-208.

9. Chen S, Yang J, Yang W, Wang C, Bärnighausen T, et al. (2020) COVID-19 control in China during mass population movements at New Year. Lancet 395(10226): 764-766.

10. La VP TH, Ho MT, Nguyen MH, P Nguyen K-L, Vuong TT, et al. (2020) Policy Response, Social Media and Science Journalism for the Sustainability of the Public Health System Amid the COVID-19 Outbreak: The Vietnam Lessons. Sustainability 12: 2931

11. Pennycook G, McPhetres J, Zhang Y, Rand D (2020) Fighting CoVID-19 misinformation on social media: Experimental evidence for a scalable accuracy nudge intervention 31(7): 770-780.

12. Huynh TL (2020) The COVID-19 risk perception: A survey on socioeconomics and media attention. Econ. Bull 40(1): 758-764.

13. Sohrabi C, Alsafi Z, O’Neill N, Khan M, Kerwan A, et al. (2020) World Health Organization declares global emergency: A review of the 2019 novel coronavirus (COVID-19). Int J Surg 76: 71-76.

14. Campos GS, Bandeira AC, Sardi SI (2015) Zika virus outbreak, bahia, brazil. Emerg. Infect Dis 21(10): 1885-1886.

15. Petersen LR, Jamieson DJ, Powers AM, Honein MA (2016) Zika virus. N Engl J Med 374: 1552-1563.

16. Holman EA, Garfin DR, Silver RC (2014) Media's role in broadcasting acute stress following the Boston Marathon bombings. Proc Natl Acad Sci 111(1): 93-98.

17. Depoux A, Martin S, Karafillakis E, Preet R, Wilder-Smith A, et al. (2020) The pandemic of social media panic travels faster than the COVID-19 outbreak. J. Travel Med 27(3): taaa031.

18. Del Rio C, Malani P N (2020) COVID-19-new insights on a rapidly changing epidemic. Jama 323(14): 1339-1340.

19. Garrett L (2020) COVID-19: the medium is the message. Lancet 395 (10228): 942-943.

20. (2020) Organization WH, Considerations for quarantine of individuals in the context of containment for coronavirus disease ('COVID-19):" interim guidance, 29 February 2020. World Health Organization.

21. Anderson RM, Heesterbeek H, Klinkenberg D, Hollingsworth TD (2020) How will country-based mitigation measures influence the course of the COVID-19 epidemic? Lancet 395(10228): 931-934.

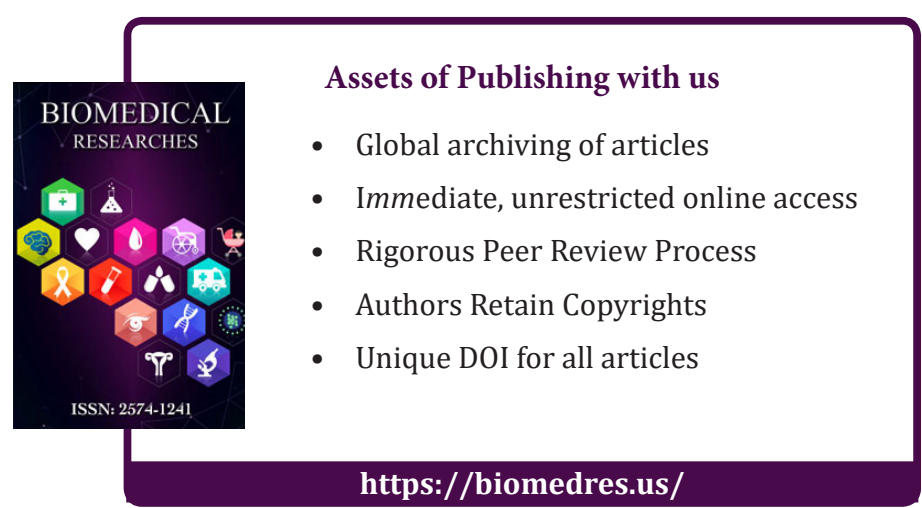

